\title{
Contact Dermatitis after Prescription of an Ophthalmic Ointment Containing Fradiomycin Sulfate: A Retrospective Database Study Using Japanese Health Insurance Claims Data
}

\author{
Naomi Sugimoto $^{1} \cdot$ Kazuhiko Kuribayashi $^{1} \cdot$ Yuji Yamamoto $^{2} \cdot$ Satoshi Nagayasu $^{2} \cdot$ \\ Osamu Suga $^{1}$ - Yoko Fujimoto ${ }^{1}$
}

Published online: 30 November 2017

(c) The Author(s) 2017. This article is an open access publication

\begin{abstract}
Background Topical ointments containing fradiomycin sulfate, such as fradiomycin sulfate/methylprednisolone ( $\mathrm{F} /$ M) and fradiomycin sulfate/betamethasone sodium phosphate $(\mathrm{F} / \mathrm{B})$, are known to cause allergic contact dermatitis (CD) in some patients, especially when used for the periocular region. F/M is commonly prescribed to patients for various conditions; however, there are no reports with respect to the incidence of $\mathrm{CD}$ caused by $\mathrm{F} / \mathrm{M}$ in actual practice.

Objective The aim was to investigate the incidence of $\mathrm{CD}$ using a data-based retrospective cohort study.

Methods Using a Japanese health insurance claims database [MinaCare Co. Ltd. healthcare database (MinaCare HDB)], a comparative assessment was conducted of $\mathrm{F} / \mathrm{M}$ and another combination drug (F/B) and two single-drug treatments (ophthalmic ointments with either an antibiotic or a steroid). The total data set consisted of 1,176,082 individuals in the MinaCare HDB, with 54,016 having received prescriptions for one of the four investigational drug regimens.

Results Overall, the incidences of $\mathrm{CD}$ were similar in three of the four groups in this study (F/M 0.091; F/B 0.092; steroids 0.102 ), while being lower in the fourth group (antibiotics 0.060). Even after confirmation of a diagnosis of $\mathrm{CD}$, prescriptions for the investigational drugs were repeatedly filled for some patients.
\end{abstract}

Yoko Fujimoto

yoko.fujimoto@pfizer.com

1 Pfizer Japan Inc., 3-22-7 Yoyogi, Shibuya-ku, Tokyo 151-8589, Japan

2 MinaCare Co. Ltd., 2-3-11 Nihonbashihoncho, Chuo-ku, Tokyo 103-0023, Japan
Conclusion This study demonstrated that there was no clear difference in the incidence of $\mathrm{CD}$ after filling prescriptions for $\mathrm{F} / \mathrm{M}, \mathrm{F} / \mathrm{B}$, and ophthalmic ointment containing a steroid, while the incidence with antibiotics was lower by 0.03-0.04 compared with the other groups. Considering the observation that the investigational drugs were repeatedly prescribed even after the diagnosis of $\mathrm{CD}$, it is critical that the risk of $\mathrm{CD}$ with these prescribed topical ointments is better understood by primary care physicians in order to take appropriate countermeasures.

\section{Key Points}

The incidence of contact dermatitis (CD) after use of fradiomycin sulfate/methylprednisolone (F/M), fradiomycin sulfate/betamethasone sodium phosphate $(\mathrm{F} / \mathrm{B})$, or an antibiotic- or steroidcontaining ophthalmic ointment drug regimen was investigated using a Japanese health insurance claim database.

Similar incidence rates of $\mathrm{CD}$ after filling prescriptions were seen in the $\mathrm{F} / \mathrm{M}, \mathrm{F} / \mathrm{B}$, and steroid groups; the incidence was lower in the antibiotic group.

The finding that the investigational drugs were repeatedly prescribed to some patients after a diagnosis of $\mathrm{CD}$ indicated the importance of increasing awareness among physicians of the risk of $\mathrm{CD}$ with these ophthalmic ointments. 


\section{Introduction}

Fradiomycin sulfate (neomycin)/methylprednisolone (F/M) (Neo-Medrol EE ointment, Pfizer Japan Inc., Tokyo, Japan) has been prescribed for the treatment of ophthalmic inflammation caused by infection, external ear eczema and dermatitis, and post-operative treatment in the otorhinolaryngology field in Japan for more than 50 years. Fradiomycin sulfate is an aminoglycoside antibiotic that is known to cause allergic contact dermatitis (CD) in some patients [1,2]. In addition to F/M, fradiomycin sulfate/betamethasone sodium phosphate $(\mathrm{F} / \mathrm{B})$ (Rinderon-A ointment, Shionogi \& Co., Ltd., Osaka, Japan) ophthalmic ointments with indications nearly identical to those of $\mathrm{F} / \mathrm{M}$ are also available.

Over the past 3 decades, CD cases showing a potential causal relationship with $\mathrm{F} / \mathrm{M}$ or fradiomycin have been reported [3-21]. However, reliance on case reports has resulted in a lack of studies on the incidence of $\mathrm{CD}$ or systematic investigations of the causal relationship with a specific drug in a large population in Japan.

The aim of this study, therefore, was to investigate the incidence of $\mathrm{CD}$ in patients with prescriptions for $\mathrm{F} / \mathrm{M}$ as compared with that for $\mathrm{F} / \mathrm{B}$ and two other drug groups of ophthalmic ointments (those containing either an antibiotic or a steroid), using the MinaCare Co. Ltd. healthcare database (MinaCare HDB), a commercial insurance claims database. The MinaCare HDB includes the data of approximately 2 million individuals with medical and pharmaceutical claims data received from employment-based health insurance companies and covers a wide range of age groups.

\section{Materials and Methods}

\subsection{Study Design}

This was a retrospective cohort study using the MinaCare $\mathrm{HDB}$ to investigate the incidence of $\mathrm{CD}$ requiring treatment after the filling of prescriptions for $\mathrm{F} / \mathrm{M}$, as compared with the incidence of $\mathrm{CD}$ after the filling of prescriptions for $\mathrm{F} / \mathrm{B}$, antibiotic ophthalmic ointments or steroid ophthalmic ointments. F/M and F/B are combination ophthalmic ointments, whereas the other two groups, which are primarily applied to the eyes, contain just one of the active ingredients listed (Table 1).

\subsection{Data Source}

The MinaCare HDB consists of medical and pharmaceutical claims data, as well as health check-up data, which have been provided by employment-based health insurance companies in Japan since 2010. The reliability of the MinaCare HDB was confirmed through a comparison with two national data sources [22].

The data from the MinaCare HDB was extracted in December 2013 for 1,176,082 individuals, of which $521,436(44.3 \%)$ were male and $654,646(55.7 \%)$ were female. As shown in Fig. 1, the age distribution of the entire MinaCare HDB showed a bimodal distribution, with a peak for children under 10 years old and a larger peak for individuals in the range of 30-40 years of age. The majority consisted of working individuals and their spouses.

\subsection{Selection of the Study Cohort and Estimation of Incidence}

Patient claim data with prescription records for one of the four investigational drug groups (without any concomitant prescriptions for the other three drug groups) were extracted. The three criteria shown in Fig. 2 were applied to select the study cohort. The incidence of $\mathrm{CD}$ was estimated based on the proportion of CD cases.

Table 1 Investigational drug groups of the ophthalmic ointments used

\begin{tabular}{|c|c|}
\hline $\begin{array}{l}\text { Drug } \\
\text { group }\end{array}$ & Active ingredient (brand name, manufacturer) \\
\hline $\mathrm{F} / \mathrm{M}$ & Fradiomycin sulfate/methylprednisolone (Neo-Medrol EE ointment, Pfizer Japan Inc., Tokyo, Japan) \\
\hline $\mathrm{F} / \mathrm{B}$ & Fradiomycin sulfate/betamethasone sodium phosphate (Rinderon-A ointment, Shionogi \& Co., Ltd., Osaka, Japan) \\
\hline Antibiotics & $\begin{array}{l}\text { Ofloxacin (Tarivid ophthalmic ointment } 0.3 \% \text {, Santen Pharmaceutical Co., Ltd., Osaka, Japan) (Ofloxin ophthalmic ointment } 0.3 \% \text {, } \\
\text { TOA Pharmaceuticals Co., Ltd., Toyama, Japan) } \\
\text { Erythromycin lactobionate/colistin sodium methanesulfonate (Erycoli ophthalmic ointment T, Nitto Medic Co., Ltd., Toyama, } \\
\text { Japan) (Ecolicin ophthalmic ointment, Santen Pharmaceutical Co., Ltd., Osaka, Japan) }\end{array}$ \\
\hline Steroids & $\begin{array}{l}\text { Dexamethasone (D.E.X ophthalmic ointment } 0.1 \% \text { T, Nitto Medic Co., Ltd., Toyama, Japan) (Santeson 0.05\% ophthalmic } \\
\text { ointment, Santen Pharmaceutical Co., Ltd., Osaka, Japan) } \\
\text { Prednisolone acetate (Predonine ophthalmic ointment } 0.25 \% \text {, Shionogi \& Co., Ltd., Osaka, Japan) (Prednisolone acetate } \\
\text { ophthalmic ointment } 0.25 \% \text { T, Nitto Medic Co., Ltd., Toyama, Japan) }\end{array}$ \\
\hline
\end{tabular}

$F / B$ fradiomycin sulfate/betamethasone sodium phosphate, $F / M$ fradiomycin sulfate/methylprednisolone 


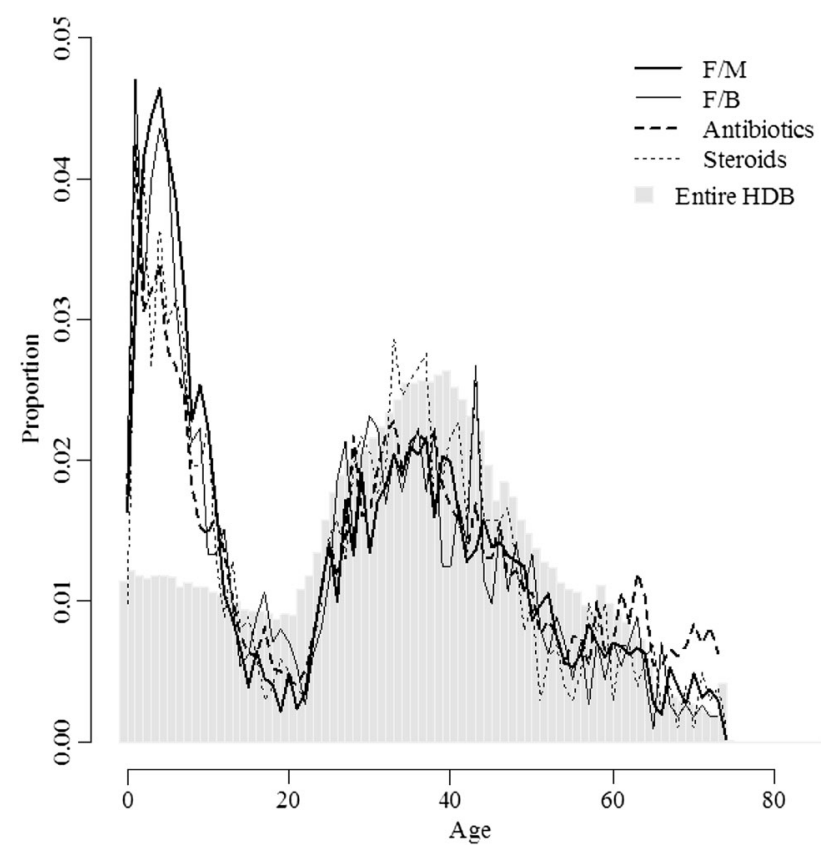

Fig. 1 Age distribution of the entire database and each investigational drug group in the MinaCare HDB. Grey bar chart: the entire database; lines: each investigational drug group. $F / B$ fradiomycin sulfate/betamethasone sodium phosphate, $F / M$ fradiomycin sulfate/ methylprednisolone, $H D B$ healthcare database

\subsection{Definition of Contact Dermatitis (CD)}

The disease and injury information in the MinaCare HDB were coded by the International Statistical Classification of Diseases and Related Health Problems, 10th revision (ICD10). The following ICD-10 codes were regarded as CD: L233, L239, L244, L249, L251, and L259. The original text of the diseases and injuries in the claims, including "contact" and "dermatitis," was also used to determine CD.

\subsection{Sensitivity Analysis}

The incidence of CD was calculated using various followup periods (1, 3, and 6 months), in order to evaluate the robustness of the comparison of the incidence rates among the investigational drug groups.

\subsection{Exploratory Analyses}

To better understand the diagnosis and treatment of CD associated with the application of ophthalmic ointment in the actual clinical setting, an exploratory analysis was performed in $\mathrm{CD}$ cases within a 12-month period before the earliest diagnosis of CD. The number of days from filling of the prescription for the investigational drugs immediately prior to the diagnosis of $\mathrm{CD}$ was classified into four groups: $\leq 30$ days, $>30$ days to $\leq 90$ days, $>90$ days to $\leq 180$ days, and $>180$ days. The frequency of patch testing for making the diagnosis, the number of investigational drug prescription fillings after the diagnosis of CD had been made, the number of patients for whom an oral steroid prescription to treat $\mathrm{CD}$ was filled, and the number of patients with prescription for anti-allergic agents were also investigated. Sub-group analyses of the incidence of CD were also performed based on sex and age group (under 20 years of age/20 years and older).

\subsection{Statistical Methods}

The analysis was primarily based on descriptive statistical methods. Summary statistics and graphical presentations were used to describe the data. The incidence of CD in each drug group was presented with a $95 \%$ confidence interval. In order to describe a deviation from the homogeneity of the incidence of CD across the drug groups, a $p$ value from the Freeman-Halton test [23] was computed. $\mathrm{R}$ [24] was used for statistical analysis.

\subsection{Anonymization of the Subjects}

This study used MinaCare's subject-level electronic healthrelated database. In this database, the identities of individuals were anonymized. MinaCare is allowed to supply such anonymized data under the data transfer contract with its client health insurers.

\section{Results}

\subsection{Age Distribution of Patients in Each Investigational Drug Group}

Of the total 1,176,082 individuals, 22,366 had a prescription filled for only F/M, 5828 for only F/B, 20,902 for only antibiotics, and 4920 for only steroids (Fig. 2).

We further sorted the data and found that the number of patients who met all three criteria in the $\mathrm{F} / \mathrm{M}$ group was 5133 (3128 females, 60.9\%). In the F/B group, 1125 patients met all three criteria (683 females, $60.7 \%$ ). In the antibiotic and steroid groups 4430 (2400 females, 54.2\%) and 1016 (661 females, 65.1\%), respectively, met all of the criteria. The percentage of females was higher than that of males in all four drug groups.

The age distributions of patients were very similar among the investigational groups, with a remarkably high proportion in the under 5- to 6-years age bracket and a less prominent peak in the age bracket of those 30-50 years old (Fig. 1). The age distribution pattern in each group, 
Fig. 2 Criteria for study cohort selection to estimate the incidence of $\mathrm{CD}$. The table shows the numbers of patients in each category. $C D$ contact dermatitis, $F / B$ fradiomycin sulfate/betamethasone sodium phosphate, $F / M$, fradiomycin sulfate/methylprednisolone
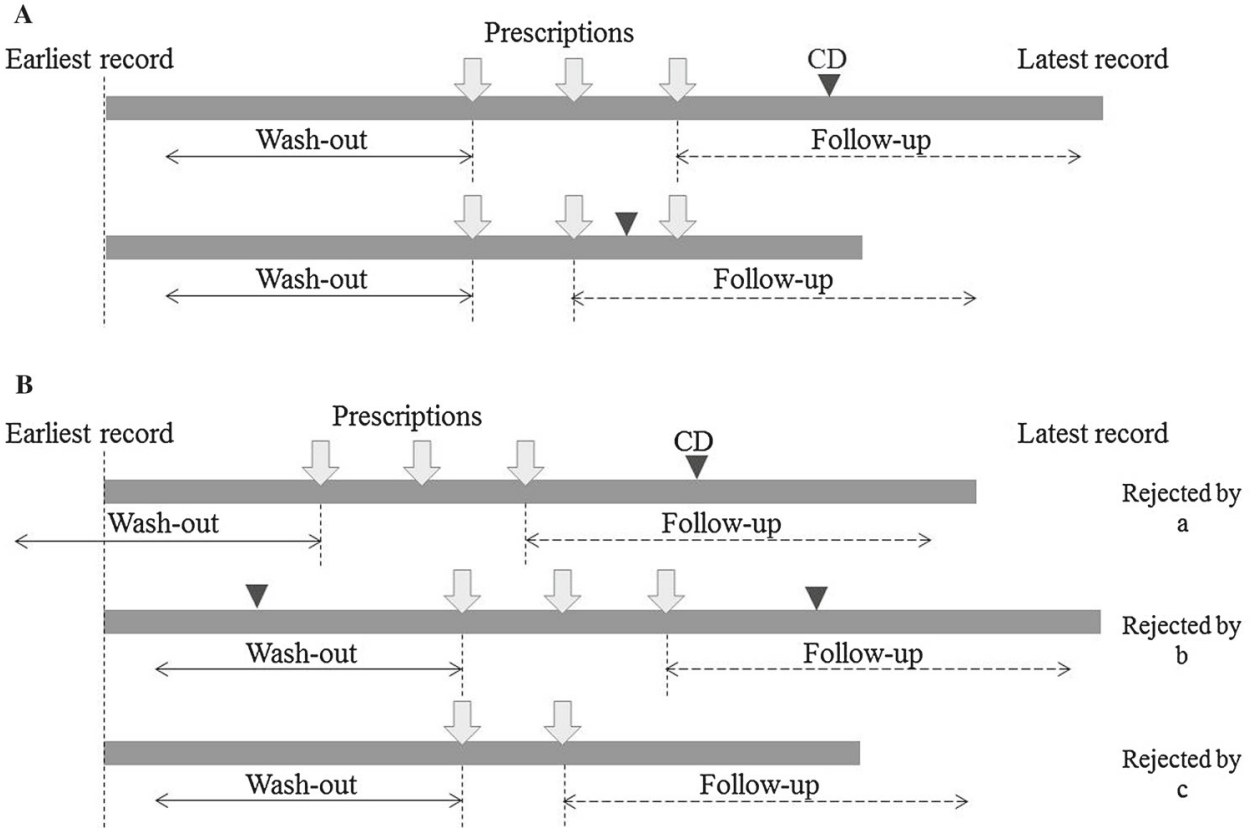

Criterion a: Identify a cohort of patients who had prescriptions for any one of the 4 drug formulations filled for the first time. Patients who had no records of prescriptions being filled for any of the 4 drugs within 6 months prior to the first-ever filling of the prescription for the drug were selected.

Criterion b: Identify a cohort of patients newly diagnosed as having CD. Patients with no prior diagnosis of $\mathrm{CD}$ before filling of the prescription for the drug for the first time were selected.

Criterion c: Identify CD cases and non-CD cases. Patients whose prescription for the drug was filled at least once within 12 months before the initial diagnosis of CD (CD cases), or who had not been diagnosed with $\mathrm{CD}$ during a period of at least 12 months (follow-up period) after filling of the most recent prescription (non-CD cases) were selected.

\begin{tabular}{llcccc}
\hline & & F/M & F/B & Antibiotics & Steroids \\
\hline \multirow{2}{*}{ Single use } & & 22,366 & 5,828 & 20,902 & 4,920 \\
\multirow{3}{*}{ Criteria } & $\mathrm{a}$ & 14,993 & 3,682 & 13,699 & 3,271 \\
& $\mathrm{a}+\mathrm{b}$ & 13,418 & 3,221 & 12,934 & 2,872 \\
& $\mathrm{a}+\mathrm{b}+\mathrm{c}$ & 5,133 & 1,125 & 4,430 & 1,016 \\
\hline
\end{tabular}

excluding those in the 0 - to 10 -years age bracket, was similar to that of the entire MinaCare HDB.

The medical conditions under which prescriptions for the investigational drugs were filled in the same month were predominantly for the treatment of ophthalmic conditions in all four groups. Major diagnoses at the initial prescription in the investigational period were similar in the F/M, F/B, and steroid groups; namely, allergic conjunctivitis or blepharitis. In the antibiotic group, ophthalmic diseases and infectious diseases such as myopic astigmatism, hordeolum, or chalazion were seen. In the F/M, F/B, and steroid groups, atopic dermatitis (9.6-14.9\%) and eczema (11.4-16.1\%) were diagnosed slightly more often than in the antibiotic group $(3.3 \%$ and $3.8 \%$, respectively).

\subsection{Incidences of CD with a 12-Month Follow-Up Period}

To investigate the frequency of the diagnosis of CD under the MinaCare HDB, patients who met the three criteria described in the Sect. 2 on incidence estimation were considered. At 12 months (365 days), the incidence of CD was 0.091 (465/5133 patients) in the F/M group, 0.092 (104/1125 patients) in the F/B group, $0.060(267 / 4430$ patients) in the antibiotic group, and 0.102 (104/1016 patients) in the steroid group $(p<0.001)$. The incidence rate of $\mathrm{CD}$ in the antibiotic group was lower than the rates in the $\mathrm{F} / \mathrm{M}, \mathrm{F} / \mathrm{B}$, and steroid groups by $0.03-0.04$. 


\subsection{Sensitivity Analyses by Follow-Up Period (1, 3, and 6 Months)}

Patients who met the three aforementioned criteria were further sorted by replacing the follow-up period of

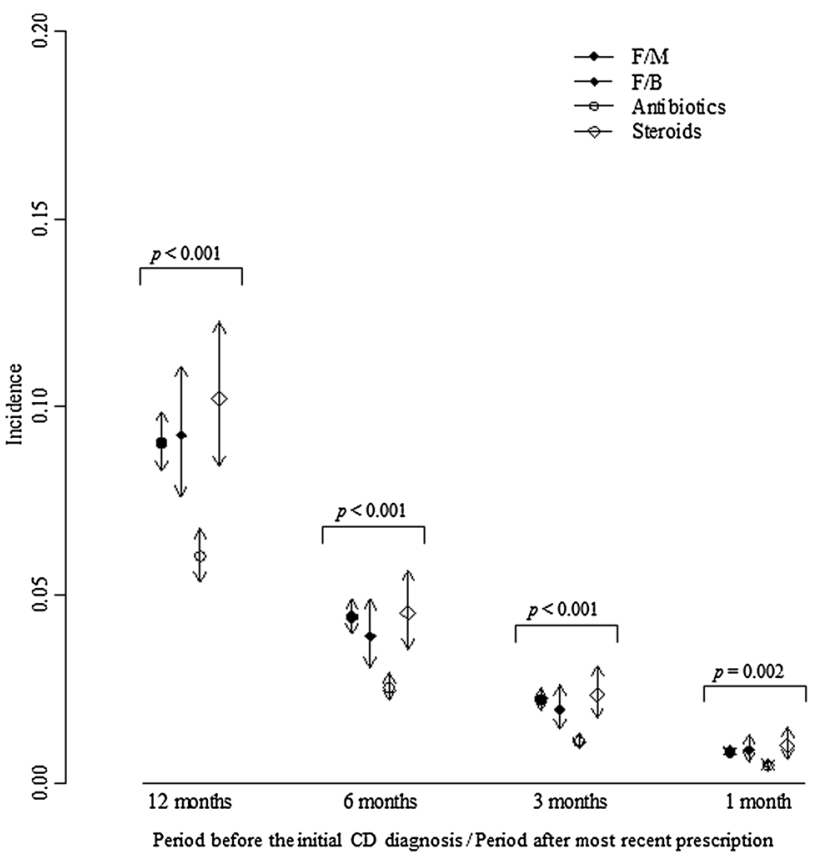

Fig. 3 Incidence of $\mathrm{CD}$ and results of sensitivity analyses. Arrows indicate the $95 \%$ confidence interval for incidence. Patient number in each investigational drug group: F/M 5133, F/B 1125, antibiotics 4430, steroids 1016. $C D$ contact dermatitis, $F / B$ fradiomycin sulfate/betamethasone sodium phosphate, $F / M$ fradiomycin sulfate/ methylprednisolone
12 months with 1,3 , or 6 months (Fig. 3). In all investigational drug groups, the number of patients decreased as the follow-up periods became shorter. At the same time, the number of patients diagnosed as having CD increased over these periods and resulted in an increased incidence rate with a longer follow-up period. The results of sensitivity analyses showed that the relative incidence rates among the investigational drug groups after 1-, 3-, 6-, and 12-month follow-up periods were similar (Fig. 3; $p$ values for 1-, 3-, and 6-month follow-up periods were $0.002,<0.001$, and $<0.001$, respectively).

\subsection{Exploratory Analyses}

A series of additional analyses were performed by targeting the patients diagnosed as having $\mathrm{CD}$ within 12 months after filling of their prescriptions for the investigational drugs (Table 2).

Of the patients who were diagnosed as having $\mathrm{CD}$, the following percentages had one or more record of ophthalmic disease before the first prescription of one of the investigational drug regimens: $51.0 \%$ (237/465), 51.0\% (53/104), 50.6\% (135/267), and 51.9\% (54/104) in the F/M, $\mathrm{F} / \mathrm{B}$, antibiotic, and steroid groups, respectively.

In all of the groups, approximately $70 \%$ of patients were diagnosed as having $\mathrm{CD}$ within 6 months of the most recent prescription. No remarkable trend in the interval between the most recent prescription and the diagnosis of $\mathrm{CD}$ was found for any of the investigational drug groups. Only $1.1-3.9 \%$ of patients received patch tests across the groups after the diagnosis of CD (Table 2).

The numbers of patients who had prescriptions for oral anti-allergic drugs filled before the $\mathrm{CD}$ diagnosis were

Table 2 Summary of exploratory analyses in patients with a diagnosis of CD during the 12-month follow-up period

\begin{tabular}{|c|c|c|c|c|}
\hline & $\begin{array}{l}\mathrm{F} / \mathrm{M} n(\%) \\
(n=5133)\end{array}$ & $\begin{array}{l}\mathrm{F} / \mathrm{B} n(\%) \\
(n=1125)\end{array}$ & $\begin{array}{l}\text { Antibiotics } n(\%) \\
(n=4430)\end{array}$ & $\begin{array}{l}\text { Steroids } n(\%) \\
(n=1016)\end{array}$ \\
\hline $\mathrm{CD}$ diagnosis & $465(9.1)$ & $104(9.2)$ & $267(6.0)$ & $104(10.2)$ \\
\hline Prescribed for "eye" & $237(51.0)$ & $53(51.0)$ & $135(50.6)$ & $54(51.9)$ \\
\hline Allergic tendency ${ }^{\mathrm{b}}$ & $73(15.7)$ & $23(22.1)$ & $45(16.9)$ & $24(23.1)$ \\
\hline $\mathrm{CD} \leq 30$ days from the most recent $\mathrm{Rx}$ & $88(18.9)$ & $23(22.1)$ & $51(19.1)$ & $22(21.2)$ \\
\hline CD 31-90 days from the most recent $\mathrm{Rx}$ & $122(26.2)$ & $22(21.2)$ & $52(19.5)$ & $24(23.1)$ \\
\hline CD 91-180 days from the most recent $\mathrm{Rx}$ & $133(28.6)$ & $26(25.0)$ & $81(30.3)$ & $27(26.0)$ \\
\hline $\mathrm{CD}>180$ days from the most recent $\mathrm{Rx}$ & $122(26.2)$ & $33(31.7)$ & $83(31.1)$ & $31(29.8)$ \\
\hline Patch test & $12(2.6)$ & $3(2.9)$ & $3(1.1)$ & $4(3.8)$ \\
\hline $\mathrm{Rx}$ after $\mathrm{CD}$ diagnosis: once & $38(8.2)$ & $9(8.7)$ & $12(4.5)$ & $3(2.9)$ \\
\hline Twice & $13(2.8)$ & $5(4.8)$ & $7(2.6)$ & $1(1.0)$ \\
\hline Three or more times & $5(1.1)$ & $3(2.9)$ & $5(1.9)$ & $1(1.0)$ \\
\hline Oral steroid $\mathrm{Rx}$ added after $\mathrm{CD}$ & $18(3.9)$ & $5(4.8)$ & $8(3.0)$ & $3(2.9)$ \\
\hline
\end{tabular}

$C D$ contact dermatitis, $F / B$ fradiomycin sulfate/betamethasone sodium phosphate, $F / M$ fradiomycin sulfate/methylprednisolone, $R x$ prescription ${ }^{a}$ Speculated based on the disease name before the $\mathrm{CD}$ diagnosis

${ }^{\mathrm{b}}$ Patients with oral anti-allergic Rx before the $\mathrm{CD}$ diagnosis 


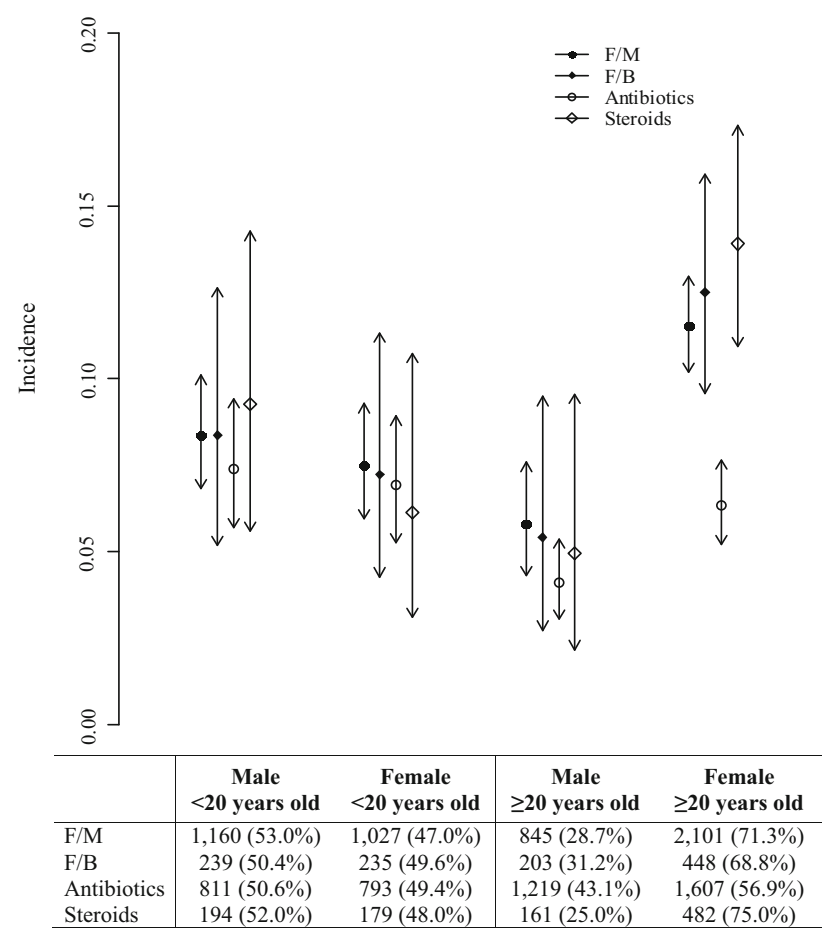

Fig. 4 Incidence of $\mathrm{CD}$ by subgroup. Arrows indicate the 95\% confidence interval for incidence. The table shows the number of patients in each category. Male and female percentages in the same age category are also shown. $C D$ contact dermatitis, $F / B$ fradiomycin sulfate/betamethasone sodium phosphate, $F / M$ fradiomycin sulfate/ methylprednisolone

similar among the investigational drug groups, and there was no correlation between the underlying allergic tendency and the incidence of $\mathrm{CD}$ in any of the investigational drug groups (Table 2).

After the diagnosis of $\mathrm{CD}$, most patients had at least one prescription filled for an investigational drug in all of the groups, excluding patients who had never filled any prescriptions. More than one prescription for the investigational drug had been filled by $3.9 \%$ (18/465) of the patients in the F/M group, $7.7 \%(8 / 104)$ in the F/B group, $4.5 \%$ (12/ $267)$ in the antibiotic group, and $1.9 \%(2 / 104)$ in the steroid group. Some patients had filled more than three prescriptions for an investigational drug. No more than $5 \%$ of patients in any of the drug groups had filled additional prescriptions for oral steroids.

When $\mathrm{CD}$ incidence rates were further analyzed, stratified by age and sex, the $\mathrm{CD}$ incidence rates in the $\mathrm{F} / \mathrm{B}, \mathrm{F} / \mathrm{M}$, and steroid groups were higher than that in the antibiotic group in females $\geq 20$ years old (Fig. 4).

\section{Discussion}

In this study, an insurance claims database was used to assess the incidence rate of $\mathrm{CD}$ requiring medication after the filling of prescriptions for F/M. To achieve this aim, we conducted a comparative assessment of four targeted drug groups in actual clinical settings. The four drug groups were ophthalmic ointment formulations of antibiotics, steroids or a combination of the two. No new product or new indications for these drug formulations have been launched or approved in Japan since 2013, and the study was conducted using the database containing the claims data for prescriptions filled before 2013. The medical conditions for which prescriptions for the investigational drugs had been filled involved predominantly the treatment of ophthalmic conditions in all four groups. The age and sex distributions of the study subjects were similar in the four groups (Fig. 1). Regarding the medical conditions, major diagnoses at the initial prescription during the investigational period were similar in the $\mathrm{F} / \mathrm{M}$ and $\mathrm{F} / \mathrm{B}$ groups. A slight difference was seen between the antibiotic group and the other three groups, which might have affected the incidence of $\mathrm{CD}$. Under the conditions of such a difference being taken into consideration in the comparison between the antibiotic group and the other groups, we think that further analyses using the data set would be valid.

Based on this database study, there were no clear differences in the incidence rate of $\mathrm{CD}$ during the 12-month follow-up period between the F/M and F/B groups. A sensitivity analysis showed the same tendency in all of the follow-up periods (Fig. 3). There is a report showing that $\mathrm{F} / \mathrm{M}$ ranks high as a topical steroid (including combination) drug with positive patch test results (seven out of 55 cases) [25]. In the present retrospective study, based on the claims database, the incidence rates of $\mathrm{CD}$ were similar in the F/B and steroid groups.

The incidence rate of $\mathrm{CD}$ was higher in the $\mathrm{F} / \mathrm{M}, \mathrm{F} / \mathrm{B}$, and steroid groups than in the antibiotic group, by 0.03-0.04. We speculated that this might have arisen from the difference in the characteristics of the patients, especially their skin conditions, which influence the selection of each drug. For example, CD generally develops more frequently at eczematous sites, and the drug groups including steroids are regarded as treatment options for eczema and are thus used more frequently than antibiotics to treat eczematous lesions. Additional analysis showed that eczema was diagnosed more frequently in the $\mathrm{F} / \mathrm{M}, \mathrm{F} / \mathrm{B}$, and steroid groups $(11.4-16.2 \%)$ than in the antibiotic group $(3.8 \%)$ at the initial prescription during the investigational period. Furthermore, the percentage of CD cases with a history of eczema before the diagnosis of $\mathrm{CD}$ in the 
Table 3 Previously reported individuals with CD suspected to be F/M related

\begin{tabular}{|c|c|c|c|c|c|c|}
\hline Author, year & Age & Sex & $\begin{array}{l}\text { Period between } \\
\mathrm{F} / \mathrm{M} \text { initiation and } \\
\mathrm{CD}^{\mathrm{a}}\end{array}$ & Objective of F/M use & $\begin{array}{l}\text { Patch test for } \\
\text { F/M (as } \\
\text { ointment) }\end{array}$ & $\begin{array}{l}\text { Patch tests for fradiomycin sulfate } \\
\text { and methylprednisolone (as } \\
\text { ingredients) }\end{array}$ \\
\hline $\begin{array}{l}\text { Arisu et al. } \\
\text { [12] }\end{array}$ & 28 & $\mathrm{~F}$ & N.D. & Erythema with periocular itching & + & $+/$ N.D. \\
\hline $\begin{array}{l}\text { Aramoto et al. } \\
{[18]}\end{array}$ & 46 & $\mathrm{~F}$ & 7 days & Itchy facial eruptions & + & $-1+$ \\
\hline $\begin{array}{l}\text { Washizaki } \\
\text { et al. [11] }\end{array}$ & 54 & $\mathrm{~F}$ & 8 months & $\begin{array}{l}\text { Edema with itching of bilateral upper and } \\
\text { lower eyelids, and bulbar conjunctiva } \\
\text { hyperemia }\end{array}$ & + & + /N.D. \\
\hline $\begin{array}{l}\text { Hino et al. } \\
{[10]}\end{array}$ & 69 & $\mathrm{~F}$ & 4 months & Periocular and eyelid itching & N.D. & + /N.D. \\
\hline $\begin{array}{l}\text { Torii and } \\
\text { Murata [7] }\end{array}$ & 5 & $\mathrm{~F}$ & 1 year & Both periocular erythema & + & N.D./N.D. \\
\hline \multirow{2}{*}{$\begin{array}{l}\text { Ishiguro et al. } \\
\text { [19] }\end{array}$} & 41 & $\mathrm{~F}$ & 4 weeks & Periocular itching & + & $+/$ N.D. \\
\hline & 74 & $\mathrm{~F}$ & 3 days & Periocular itching & + & $+/$ N.D. \\
\hline $\begin{array}{l}\text { Kambara } \\
\text { et al. [20] }\end{array}$ & 46 & $\mathrm{~F}$ & 2 years & Periocular pruritic rash & - & $+/$ N.D. \\
\hline \multirow[t]{2}{*}{ Nishioka [15] } & 19 & $\mathrm{~F}$ & N.D. & Unknown periocular disease & + & $+/$ N.D. \\
\hline & 11 & $\mathrm{~F}$ & N.D. & Unknown periocular disease & + & N.D./N.D. \\
\hline $\begin{array}{l}\text { Nagaoka et al. } \\
\text { [14] }\end{array}$ & 29 & $\mathrm{~F}$ & 8 months & Allergic conjunctivitis & + & $-1+$ \\
\hline \multirow{2}{*}{$\begin{array}{l}\text { Tsunoda and } \\
\text { Kagatani } \\
{[6]}\end{array}$} & 13 & M & 2 months & Aggravation of mainly-periocular rash & + & $-1+$ \\
\hline & 72 & $\mathrm{~F}$ & N.D. & $\begin{array}{l}\text { Erythema due to marginal blepharitis, and } \\
\text { post cataract operation }\end{array}$ & + & $+/+$ \\
\hline $\begin{array}{l}\text { Inoue and } \\
\text { Matsunaga } \\
{[4]}\end{array}$ & 60 & $\mathrm{~F}$ & N.D. & Periocular itching & N.D. & $+/$ N.D. \\
\hline $\begin{array}{c}\text { Tsunoda and } \\
\text { Okuno [5] }\end{array}$ & 28 & $\mathrm{~F}$ & 1.5 years & Periocular rash & + & $+/$ N.D. \\
\hline Shono [9] & 8 & $\mathrm{~F}$ & 3 weeks & Periocular dermatitis & N.D. & $+/$ N.D. \\
\hline $\begin{array}{l}\text { Inaba et al. } \\
{[3]}\end{array}$ & 4 & M & 1 year & Allergic conjunctivitis & - & $+/$ N.D. \\
\hline $\begin{array}{l}\text { Tsuruta and } \\
\text { Matsunaga } \\
{[16]}\end{array}$ & 4 & $\mathrm{~F}$ & N.D. & Periocular rash & N.D. & N.D./N.D. \\
\hline $\begin{array}{l}\text { Hirokawa } \\
\text { et al. }[8]\end{array}$ & 57 & $\mathrm{~F}$ & N.D. & Rash around the eyelids & + & $+/$ N.D. \\
\hline $\begin{array}{l}\text { Matsuura } \\
\text { et al. [21] }\end{array}$ & 63 & M & 9 days & Redness and swelling around eyelids & + & $+/$ N.D. \\
\hline $\begin{array}{l}\text { Tonooka and } \\
\text { Nakata [17] }\end{array}$ & 54 & $\mathrm{~F}$ & 3 days & Right periocular rash & + & N.D./N.D. \\
\hline $\begin{array}{l}\text { Yokozeki } \\
{[13]}\end{array}$ & 72 & $\mathrm{~F}$ & 2 years & Edematous erythema with periocular itching & N.D. & $+/$ N.D. \\
\hline
\end{tabular}

$C D$ contact dermatitis, $F$ female, $F / M$ fradiomycin sulfate/methylprednisolone combination ointment, $M$ male, $N . D$. not described or determined

${ }^{a}$ Including cases with exacerbation, no recovery or relapse after $\mathrm{F} / \mathrm{M}$ initiation, or relapse due to repeated use and discontinuation of $\mathrm{F} / \mathrm{M}$

antibiotic group was similar to that in the other groups $(\mathrm{F} /$ M $20.0 \%, \mathrm{~F} / \mathrm{B} 21.2 \%$, antibiotics $15.7 \%$, and steroids $13.5 \%$ ). Based on these results, we think the lower $\mathrm{CD}$ incidence rate in the antibiotic group might be explained by other drugs having been prescribed for eczematous lesions, including $\mathrm{CD}$. Considering the potential bias in drug selection, such as the characteristics of the patients, we advocate not taking this low CD incidence rate into consideration when interpreting the slight difference in rates between the antibiotic group and the other three groups. Furthermore, it merits emphasis that treatment warnings are equally necessary for all investigational drugs reviewed in this study. 
As for the demographic information of patients who had filled prescriptions for the investigational drugs, our results showed their age distributions to be similar to that of the entire MinaCare HDB (Fig. 1). However, the results obtained in this study are not applicable to elderly patients based on the subject composition of this database.

The present results showed that the incidence rates of $\mathrm{CD}$ in males and females in the antibiotic group did not differ among age groups. On the other hand, the incidence rates of $C D$ in females $\geq 20$ years old were higher than the rates in the male groups and in females $<20$ years old for the other three investigational drug regimens (Fig. 4). The proportions of females $\geq 20$ years old who filled prescriptions for drugs in the $\mathrm{F} / \mathrm{M}, \mathrm{F} / \mathrm{B}$, and steroid groups were higher $(68.8-75.0 \%)$ than the proportion in the antibiotic group $(56.9 \%)$. This may suggest a tendency for females $\geq 20$ years old to pay closer attention to their skin conditions, and the higher incidence rates of CD in these three drug groups may reflect the higher proportion in the study population of females $\geq 20$ years old.

Case reports of $\mathrm{CD}$ related to $\mathrm{F} / \mathrm{M}$ are summarized in Table 3 [3-21]. Based on the information obtained, the reported number of female patients was larger than that of male patients, and the majority of patients $\geq 20$ years old were female, which is similar to the results obtained in this study. Although it is presently unclear why a greater incidence of $\mathrm{CD}$ is reported in females $\geq 20$ years old who filled prescriptions for drug formulations that contained steroids rather than antibiotics, it is assumed that this group's interest in cosmetics attributes to their awareness of dermatological care and they are therefore more sensitive to the dermatological symptoms associated with the use of steroids. Furthermore, this could also be explained by an already existing risk factor like an eczematous lesion or CD associated with cosmetics, such as eye make-up products.

The present results showed that the patch tests that should be performed at diagnosis, as clearly stated in the CD treatment guidelines [26], are not performed as recommended (Table 2). This raises the possibility that the patch test was only performed when identification of the causal drug was absolutely necessary.

It was also found that the same prescription was filled repeatedly after the diagnosis of $\mathrm{CD}$ had been made, despite the prescribed drug being suspected to have caused the CD (Table 2).

Herein, we have presented the incidence rates of $C D$ caused by specific drugs, based on our analysis of the MinaCare HDB. The MinaCare database reflects the health status of those enrolled in employment-based health insurance and provides a large sample size with a broad age distribution. This database may serve as a reliable tool for post-marketing evaluations of drugs.
The significance of this study is that it explored the incidence of CD associated with treatment in actual clinical practice, based on analysis of prescription records in Japan, as compared to the conventional analysis of case reports for which the antigen had already been identified by patch tests $[1,2,25]$. However, this database study has several limitations. The first limitation is that the incidence rate of $\mathrm{CD}$ was calculated only for patients who visited hospitals and were diagnosed by doctors as having CD. There may be a large pool of patients who actually had CD but did not visit the hospital and therefore went undiagnosed and unrecorded. The second limitation is that the information in the claims data in the MinaCare HDB is limited. The severity of the disease, causal relationship of the investigational drug formulations with the disease, and patient adherence to dispensed drugs or the frequency of dispensed drug use by the patients (and possibly by other family members) are not fully documented in the HDB. Regarding the objective of prescribing the investigated drugs, the possibility that the prescriptions for $\mathrm{CD}$ include uses for treating other disorders cannot be denied. In addition, the lack of patch testing makes it difficult to prove the direct association with $\mathrm{CD}$. The causal relationships between the investigational drug formulations and $\mathrm{CD}$ require primarily evaluation based on whether the disease occurred before or after prescription of the investigational drug regimens. Because the site of CD is not reported in the HDB, there is a possibility of CD unrelated to the investigated drugs observed at sites other than the eyes having been included in the incidence. Since only data associated with the targeted investigational drugs were analyzed, no other factors such as concomitant medications or non-drug allergens that could have caused $\mathrm{CD}$ have been taken into account in the present study. According to a report on patch tests using the Japanese Standard series in CD patients, the positive rate at $72 \mathrm{~h}$ was very high for metals such as nickel sulfate or cobalt chloride (18-19\%), and 2-8\% of those examined showed a positive reaction to fragrance mix, paraben mix, $p$-phenylenediamine-free base or lanolin alcohol [27]. Wearing make-up or accessories, in other words exposure to these allergens, might have led to the higher incidence rate of $\mathrm{CD}$ observed in females in this study. In addition, the diagnosis based on the disease codes may not reflect the actual medical records. To overcome such limitations and reduce bias, we took two approaches. We set the washout and follow-up periods, and evaluated the results through a comparison with proper comparator drugs under the same conditions. By taking these two approaches, we believe that the relationships between the dispensed investigational drugs and the diagnoses of CD were appropriately estimated.

In countries such as Germany that have information networks on contact allergies [28], the prevalence and risk 
assessments of contact allergy have been made on the basis of the surveillance results for topical drugs [29-32]. In Japan, however, no such system currently exists and it is difficult to obtain nationwide surveillance information. We therefore believe that the results of this study provide valuable large-scale real world data, despite the limitations mentioned above.

\section{Conclusions}

We assessed the incidence of $\mathrm{CD}$ requiring medication after prescriptions for topical drugs had been filled in actual clinical settings, using the MinaCare HDB. We found that the incidence of $\mathrm{CD}$ that required any form of treatment after the filling of a prescription for F/M was similar to that for $\mathrm{F} / \mathrm{B}$ and ophthalmic ointments containing a steroid, and slightly higher than that for an antibiotic. The study also revealed that the investigational drugs were repeatedly dispensed after the diagnosis of CD. It is critical for primary care physicians to have a better understanding of the risk of $\mathrm{CD}$ due to these prescribed ophthalmic ointments, and they should take appropriate measures such as stopping the use of the possible prescribed causative drug or antigen when encountering patients who have developed dermatitis. Additionally, as recommended by the guidelines, identification of the causative drugs and ingredients using patch tests after $\mathrm{CD}$ has developed is important for avoiding further exposure to the allergens [26, 33].

\section{Compliance with Ethical Standards}

Funding No external or internal sources of funding were used for this study.

Conflict of interest Naomi Sugimoto, Kazuhiko Kuribayashi, Osamu Suga and Yoko Fujimoto are full time employees of Pfizer Japan Inc. Yuji Yamamoto is the founder and CEO of MinaCare Co. Ltd., and Satoshi Nagayasu was an employee of MinaCare Co. Ltd. at the time of the study.

Open Access This article is distributed under the terms of the Creative Commons Attribution-NonCommercial 4.0 International License (http://creativecommons.org/licenses/by-nc/4.0/), which permits any noncommercial use, distribution, and reproduction in any medium, provided you give appropriate credit to the original author(s) and the source, provide a link to the Creative Commons license, and indicate if changes were made.

\section{References}

1. Kawai N, Yagami A, Inaba Y, Nakagawa M, Matsunaga K. A case of contact dermatitis due to fradiomycin sulfate. Jpn J Dermatol. 2009;119:2030.

2. Kambara T, Sugimoto M, Takeshita Y, Takahashi K. A case of contact dermatitis due to diphenhydramine hydrochloride and fradiomycin sulfate. Environ Dermatol. 2000;7:245-9 (in Japanese).

3. Inaba $Y$, Nakagawa $M$, Matsunaga $K$. Common side effects of topical steroids. 3) Others, Case 12: contact dermatitis due to combination drug. Vis Dermatol. 2009;8:154-5 (in Japanese).

4. Inoue T, Matsunaga K. You must know these skin diseases. Part 1. Erythema, edema and papules of the head and neck and the periocular area. Vis Dermatol. 2006;5:859-60 (in Japanese).

5. Tsunoda T, Okuno K. Contact dermatitis easy to be overlooked. J Environ Dermatol. 2006;13:7-14 (in Japanese).

6. Tsunoda T, Kagatani S. Two cases of contact dermatitis due to methylprednisolone. J Environ Dermatol. 2005;12:196-201 (in Japanese).

7. Torii Y, Murata K. Database of cases with side effects. New trial of presentation of drug information. Ophthalmic remedies. A case of atopic dermatitis that caused contact dermatitis due to fradiomycin sulfate and methylprednisolone eye ointment. Diagn Treat. 1996;84:720 (in Japanese).

8. Hirokawa K, Kameyama R, Nakagawa M, et al. Patch test results of cosmetic products and allergens in 2007. J Environ Dermatol Cutan Allergol. 2010;4:89-98 (in Japanese).

9. Shono M. Prick test and patch test. Pediatr Jpn. 2008;49:75-82 (in Japanese).

10. Hino H, Makino S, Kitahara H, Okada Y. Database of side effect cases. New trial of presented drug information. A case of contact dermatitis due to amlexanox $\left(\right.$ ELICS $\left.^{\circledR}\right)$ ophthalmic solution. Diag Treat. 1996;84:740 (in Japanese).

11. Washizaki K, Koseki M, Kanto H, Ito M. A case of contact dermatitis due to Catalin k eye drops. Skin Res. 1993;35:337-43 (in Japanese).

12. Arisu K, Ogino Y, Suzuki M, Matsunaga K, Hayakawa R. Contact dermatitis and patch test XI. The 14th annual meeting of the Japanese Society for Dermatoallergology and Contact Dermatitis: studies on contact dermatitis due to topical medicaments in 1988. Skin Res. 1990;32:205-11 (in Japanese).

13. Yokozeki H. Aiming for total management of allergy: guideline for allergic diseases and its application. Mod Physician. 2013;33:183-7 (in Japanese).

14. Nagaoka $\mathrm{Y}$, Tsuchiya $\mathrm{T}$, Matsuo $\mathrm{K}$, et al. A case of contact dermatitis due to methylprednisolone. Jpn J Clin Derma. 2003;57:31-2 (in Japanese).

15. Nishioka K. Skin care and topical treatment of atopic dermatitis from the viewpoint of a dermatologist. Skin Res. 2000;42:75-83 (in Japanese).

16. Tsuruta K, Matsunaga K. Feature articles: skin diseases in children: listen to specialists. II. Eczema/dermatitis/urticaria-contact dermatitis. J Pediatr Pract. 2009;72:1979-85 (in Japanese).

17. Tonooka E, Nakata T. Dark red erythema with right eye erosion and scales. Vis Dermatol. 2013;13:21-2.

18. Aramoto Y, Uemura T, Akiyoshi E, Murata Y, Kawashima M. A case of contact dermatitis due to methylprednisolone. J Dermatol. 1992;19:375-7.

19. Ishiguro H, Ogasawara M, Umebayashi Y. Contact dermatitis due to fradiomycin. Hitachi Med J. 1998;35:119-23 (in Japanese).

20. Kambara T. A case of contact dermatitis due to diphenhydramine hydrochloride and fradiomycin sulfate. Environ Dermatol. 2000;7:245-9.

21. Matsuura M, Ikezawa Y, Ito A, Kakemizu N. A case of contact dermatitis syndrome due to multiple ophthalmic solutions. Jpn J Clin Derma. 2013;67:200-4 (in Japanese).

22. Shima D, Ii Y, Yamamoto Y, Nagayasu S, Ikeda Y, Fujimoto Y. A retrospective, cross-sectional study of real-world values of cardiovascular risk factors using a healthcare database in Japan. BMC Cardiovasc Disord. 2014;14:120. 
23. Freeman GH, Halton TR. Note on an exact treatment of contingency, goodness of fit and other problems of significance. Biometrika. 1951;38:141-9.

24. R Core Team. R: a language and environment for statistical computing. R Foundation for Statistical Computing, Vienna, Austria. http://www.r-project.org/. Accessed Sept 2014.

25. Suzuki K, Matsunaga K, Suzuki R, et al. Patch test results of topical medicaments for a 5-year duration from April 1993 to March 1998. Environ Dermatol. 1999;6:216-27.

26. Takayama K, Yokozeki H, Matsunaga K, et al. Guideline for the diagnosis and treatment of contact dermatitis. Jpn J Dermatol. 2009;119:1757-93 (in Japanese).

27. Hizawa T. Group study of the optimum patch testing concentrations of skin whitening agents and the results of patch testing with standard allergens of the Japanese Society for Contact Dermatitis in 2003. J Environ Dermatol. 2005;12:137-42.

28. Schnuch A, Geier J, Lessmann H, Arnold R, Uter W. Surveillance of contact allergies: methods and results of the Information Network of Departments of Dermatology (IVDK). Allergy. 2012;67:847-57.
29. Uter W, de Pádua CM, Pfahlberg A, Nink K, Schnuch A, Lessmann $\mathrm{H}$. Contact allergy to topical corticosteroids-results from the IVDK and epidemiological risk assessment. J Dtsch Dermatol Ges. 2009;7:34-41.

30. de Pádua CA, Schnuch A, Nink K, Pfahlberg A, Uter W. Allergic contact dermatitis to topical drugs-epidemiological risk assessment. Pharmacoepidemiol Drug Saf. 2008;17:813-21.

31. de Pádua CA, Uter W, Schnuch A. Contact allergy to topical drugs: prevalence in a clinical setting and estimation of frequency at the population level. Pharmacoepidemiol Drug Saf. 2007; $16: 377-84$.

32. de Pádua Menezes CA, Schnuch A, Lessmann H, Geier J, Pfahlberg A, Uter W. Contact allergy to neomycin sulfate: results of a multifactorial analysis. Pharmacoepidemiol Drug Saf. 2005;14:725-33.

33. Takayama K. Japanese guideline for care of contact dermatitis: the guess and identification of allergens. Arerugi. 2012;61:175-80 (in Japanese). 